\title{
Luxury Fashion Brands and Furniture Design: Investigating Strategic Associations
}

\author{
Federica Codignola, (PhD) \\ Università degli Studi di Milano - Bicocca, Milan, Italy
}

Doi: 10.19044/esj.2018.v14n4p44 URL:http://dx.doi.org/10.19044/esj.2018.v14n4p44

\begin{abstract}
The recent phenomenon of the modest growth in the personal luxury goods market has created an urge to face difficulties through innovative brand and marketing communication strategies. This paper examines the potentialities of strategic associations between luxury fashion brands and furniture design. The research question to be here examined is whether synergies with furniture design can represent possible innovative strategic instruments useful to compete in the global sector of the luxury fashion industry. To do so, this paper firstly examines the congruencies and the existent associations between fashion and design. Secondly, it compares luxury fashion brands with the specific furniture design market in order to verify whether and how such inter-sectoral convergence may effectively produce fluxes of value. Results indicate that the association between luxury fashion brands and collectible furniture design in particular is the most fruitful. The value of luxury brands is enhanced and consumers are provided at the same time with innovative and creative luxury experiences.
\end{abstract}

Keywords: Creative industries; luxury fashion brands; furniture design; value creation; collaboration

\section{Introduction}

The luxury goods market, with its global economic relevance, continues to be a field of great interest for practitioners as well as for researchers. Nevertheless, in 2016 the segment of personal luxury goods showed a modest growth, a 'new normal' in which luxury firms no longer profited from prodigal consumers and a positive market (Bain \& Company, 2016). In order to be competitive and successful, luxury brand managers must then take into account current market dynamics and find new solutions. For instance, if the traditional key assets of the luxury fashion industry (i.e., its exclusivity or craftsmanship) are no longer satisfactory, or taken alone do not add any value to a brand, managers must fascinate the consumer with other 
means.

By taking into account the particular field of the cultural industries, it would be interesting to identify how in such a difficult scenario different sectors, for example fashion and design, can meet in order to mutually enhance their circuits of value. Some studies have demonstrated that in order to confront such new global challenges, luxury fashion firms may discover strategic opportunities in art (Codignola, 2016). In fact, thanks to its nature, art can concurrently convey an aura of culture, exclusivity, prestige and luxury. In addition, it inspires creativity (Eisner, 2002), which can be used as an essential element to enhance satisfaction alongside with personal experience. Several studies have shown that the link between luxury fashion firms--and luxury fashion brands (thereafter referred to LFBs)--and art is on the rise. Buyers of the former are frequently buyers of the latter. For instance, in order to show their social status and wealth, consumers from emerging economies and 'high-net-worth individuals' are often characterized by this particular purchasing inclination to integrate both luxury goods and art works. Moreover, as is the case with luxury items, one of the primary economic features of the art market is that it is -theoretically-- based on the scarcity of supply. "The art market is supply-driven and depends fundamentally on the limited amount of high-quality art works offered on the market. As a consequence, a feature of the art works is their high prices" (Codignola, 2016, p. 52). Just as for luxury goods, this means that only high-end individual buyers can afford to buy and collect art works.

Given their symbolic connotation and aesthetic value, high-quality furniture design items are today more and more perceived as art works, exchanged in art auctions or fairs, purchased by collectors, exhibited in galleries or museums. At the same time, furniture design goods by nature show some divergences from conventional art works (i.e., functionality, reproducibility, etc.) and some similarities with fashion goods. In sum, by observing the luxury fashion sector, one may then find more than one interesting intersection with the furniture design sector. For these reasons, taking into account the furniture design sector within its specific market features and goods, this paper argues that through furniture design LFBs can develop engaging creative and innovative brand and marketing communication strategies. Compared to art, such strategies would in fact be able to add value and strengthen LFBs' luxury features in an even more effective way.

The research question to be here examined is whether synergies with furniture design can represent possible innovative strategic instruments useful to compete in the global sector of the luxury fashion industry. To do so, this paper firstly analyses some luxury fashion brands industry's fundamental concepts, features, and issues. Secondly, it examines the congruencies and the 
existent associations between fashion and design. Thirdly, it compares LFBs with the specific furniture design market in order to verify whether such intersectoral convergence may effectively produce fluxes of value. More specifically, this third section aims: 1) at identifying past or existing cases of LFBs and furniture design blending; 2) at investigating the specific furniture design market within its intrinsic peculiarities and its current market features; 3 ) at generating innovative and achievable brand and marketing communication insights.

This paper refers to literature on luxury and luxury fashion brands alongside with theories regarding the cultural and creative sector. Moreover, it refers to some empirical evidence, and practitioners data. In fact, since there is a strong lack of managerial and marketing research on the topic of collaboration between fashion and furniture design, this study uses theoretical references and published documents based on reports, press articles, academic journals, books and the Internet. Fieldwork was also conducted in Milan and Paris through direct observation, self-analysis participant observation, conversations and interviews of diverse levels of formality and informality with fashion and design-related actors, and art auctions professionals.

\section{Literature review and theoretical framework Meanings of luxury and implications for luxury fashion brands}

Since the late Nineties, the personal luxury goods market, which encompasses luxury fashion goods, has always been very important in terms of the value of sales (Bain \& Company, 2016). Some studies have emphasized how, regardless of the luxury product or service category, luxury supply gives consumers the highest experiential and symbolic profits (i.e., social prestige or recognition, etc.), deriving both from the intangible assets of their brands (Kapferer \& Bastien, 2009). Subsequently, literature has identified luxury brands as a specific industry segment (Okonkwo, 2009). Therefore, luxury branding today represents a contemporary strategic issue in managerial and marketing literature (Seo \& Buchanan-Oliver, 2015; So, Parsons \& Yap, 2013). In addition, as the luxury brand market went through a remarkable change linked to the overall luxury sector transformation, different luxury brand studies have focused on the observation of the strategic role of the luxury brand identity (Heine, 2010; Keller, 2009) and on the image analysis of luxury brands (Matthiesen \& Phau, 2005).

It should also be noted how there is still some uncertainty over the concept of 'luxury'. For instance, the association of luxury with 'unnecessary' and 'superfluity' may be confusing (Dubois et al., 2001; Hansen \& Wanke, 2001), because luxury is also implicitly designed to please and satisfy particular individuals' needs that are linked to desires (Berry, 1994). As a consequence, the luxury of a product is not based purely on its accessibility 
but is also rooted in the individual's desire for such product. In fact, luxury consumers are strongly motivated in their buying decision process by psychological and social needs, such as the enforcement of self esteem or of social prestige (Nia \& Zaichkowsky, 2000). As a consequence, other than possessing higher quality and unique design a luxury product must also transmit a precise symbolic meaning which, for example, can be represented by the story (or ' $a$ ' story) linked to the product (Seo \& Buchanan-Oliver, 2015). Some scholars have identified 'branding' as the appropriate strategy meant to add such types of value to the firm's products (Holt, 2004). In particular, in order to succeed in luxury fashion brand building, researchers have highlighted the effectiveness of the following luxury products general features: the high level of quality, price, aesthetics, extraordinariness, symbolic meaning and rarity (Wiedmann et al., 2007).

In sum, alongside objective and tangible luxury fashion product features, the consumer's subjective and intangible perceptions are also relevant, if not more significant. In fact, it has been shown that luxury global firms compete to gain a stronger consumer perception which is predominantly shaped by intangible assets (Catry, 2003; Phau \& Prendergast, 2000).

\section{New challenges for the luxury fashion brand industry}

Some of the above mentioned luxury product features are now called into question (Seo and Buchanan-Oliver 2015). This market was traditionally related to small-size artisanal businesses based on assets such as craftsmanship and high quality. Nowadays globalization, the growth of its market size, the rise of multinational groups, the diversification of its product range and the enlargement and diversification of its demand, have made the luxury brand industry switch towards new market strategies. These are more and more directed at amplifying their customer base (Chadha \& Husband, 2007) and attracting middle-class consumers (Truong et al., 2009). Given these particular industry conditions and a challenging new customer base, LFBs must account for some transformations. Some scholars believe that the best marketing strategies for today's luxury fashion firms are those capable of implementing their markets, preserving positive impressions, and upholding brand value (Karpik \& Scott, 2010).

The problem is that, as stated before, some of the most representative intangible luxury fashion values are today questioned. For instance, the mass production of luxury fashioned goods unavoidably corresponds to a significant variable that threatens brand exclusivity, brand valorisation, and brand impression (Kapferer, 2012). As a result, luxury fashion firms struggle to distinguish their products as exclusive, rare, and attractive. Concurrently, they have to gratify a global yet heterogeneous demand emerging day by day from newer and larger markets. In sum, alongside with the ability to manage the 
growing diversity of markets and sales channels, firms must be ready to reinvent models that meet the expectations and the needs of more numerous and better informed and refined customers. In that respect, luxury market reports highlight significant trends such as an improved consciousness about quality investments shown by consumers and a growing new interest regarding specific features of consumption and products, for instance innovation, creativity, emotion, lifestyle and experience (Bain \& Company, 2016; The Boston Consulting Group, 2010).

In sum, to be perceived as prestigious or exclusive while concomitantly solving the urges of larger and diverse global markets, luxury fashion firms must blend the commercial and creative aspects of their businesses whilst valuing symbolic and intangible brand assets. LFBs must then compete through intangible assets such as aesthetic features and creative contents (Karpik \& Scott, 2010). Several studies have also emphasized the relevance of consumer experiences in luxury branding (i.e., Atwal \& Williams, 2009). In fact, as luxury brands are hedonic in their nature, luxury brand experiences improve luxury brands' value while allowing consumers to live an experience of sensory fulfilment (i.e., through 'visuality') (Mirzoeff, 2006). For instance, the retail space enhances the sense of experience because it dynamically engages the consumer's imagination by directly involving it with the designer, the product, and the brand (Potvin, 2009; Quinn, 2003).

As visuality deals with aesthetics, creativity, hedonism and experience, it then becomes a key strategic factor in value-creation. Through symbols and images, visuality can in fact influence the consumer's senses while creating empathy and prevailing over the mere tangible products' aspects (Mirzoeff, 2006). As a result, thanks to visuality the association of LFBs with other symbolic and aesthetic references may be more easily understood by consumers and lived as a complete and fulfilling experience. Breward \& Gilbert (2006) have identified a range of visual-related associations linking some contemporary artists to some global LFBs and have shown how customer involvement with the brands was positively affected. The two authors maintain that such associations have also been recognized as particularly functional in building innovative and creative brand strategies designed to improve the performance of global spaces of consumption (i.e., flagship stores in global fashion cities, etc.). Recent works have in fact investigated the potentialities of specific interconnections between fashion and art (Codignola, 2016; Currid, 2007). On the contrary, there is still a lack of a comprehensive research on the topic of strategic interconnections between fashion and design.

\section{Connections between fashion and design}

Industries that generate cultural goods, or goods abounding in 
symbolic and aesthetic content, connect more easily with consumers' desires and expectations (Lash \& Urry, 1994). In order to enhance the perceived value of their production and to engage with their consumers, these firms can employ different strategies. This paper focuses on value creation strategies that concern creative-oriented industries. In particular, it investigates how mutual connections across two diverse creative production industries harmoniously concur to enforce brand appreciation and consumption.

Fashion and design share the idiosyncratic and symbolic nature of their goods and are intensely affected by the time and space dimensions for the organization of production and commercialization. Moreover, fashion and design manoeuvre in similar creative-oriented consumer market segments; therefore they perform in quite systematized creative sets made of very similar features and circuits where some homogeneous fluxes of value circulate.

In that respect the following examples might be particularly significant: the commercial, social, and symbolic rituality intrinsic to the canonical fashion and design weeks around global cities (i.e., the 'Paris Fashion Week' or the 'Milano Fashion Week'); the trade fairs which take place especially in Paris (i.e., 'Maison \& Objet', etc. for design and 'Made in France', 'Interfilière Paris', etc. for fashion) and in Milan (i.e., 'Salone del Mobile', etc. for design and 'White Milano', etc. 'for fashion); the long series of a main event's collateral events that more and more turn into mundane and glamorous social ceremonies (i.e., the after-show-parties during fashion weeks or the cocktails in special locations or showrooms offered by design firms during design weeks, etc.); the media and social media extraordinary coverage and dissemination; the creative spaces such as the ateliers or the commercial spaces such as the showrooms; the so-called design or fashion-districts and capitals; a star system constituted by the super-designers or what Santagata (2004) calls the 'creative geniuses'; the seasonal or extra-seasonal products' collections; the historical or cultural trends and movements (i.e., the Eighties in fashion or the Bauhaus in design); the country of origin symbolic connotations functioning as value-multipliers (the made in France or the made in Italy, etc.); the fundamental role of public relation agencies--or spokespersons--and more and more of the new 'democratized communicational public figures' such as bloggers, influencers, etc.; the extraordinary success, once again especially in Milan and Paris, of fashion and design-focused educational organizations (specialized master degrees, universities, professional schools) in terms of the number and the international origin of students; the importance of the relative trade associations.

Although fashion and design can collaborate to produce, enhance, and use the perceived value of creative items for consumers --as it has been demonstrated with regard to fashion and art--, creative inter-sectoral collaborations have not been sufficiently investigated in managerial and 
marketing literature. Complementarities have not been properly examined neither from an economic point of view nor from a symbolic one. Nevertheless, they might be of dramatic importance in order to recognize the emerging paths of contemporary cultural and creative sectors and to understand how distant activities such as design and fashion may create connections between their firms, products, and brands in order to generate value as profit.

In order to define the European creative economy, authors often use the industry-based approach, described as the "CCIs model" (culture and creative industries). This model was established in The Economy of Culture in Europe Report by KEA (2006) after the 'concentric circles model' theorized by Thorsby (2001). As this paper investigates two European creative industries (Italy and France) and draws its empirical part from Paris and Milan, the European-based model seems appropriate. This model suggests that cultural goods and creative ideas derive from core creative cultural and artistic activities. It also suggests that these ideas spread through various circles or levels, with their share of cultural and commercial content diminishing as one proceeds away from the centre.

The model is structured by four levels of creative economy. If the activities and the production of art and of cultural organizations are at the core, the creative industries, namely design-based sectors (i.e., fashion, architecture, industrial/furniture/interior design, etc.), are at the third level. This level encompasses both production-oriented and service activities that generate goods with functional scopes, but which are also strongly founded on intellectual property and hold intense aesthetic meaning. Some authors have shown how cultural industries are defined by practices of 'reflexive accumulation' in which goods are blended with symbolic contents (Lash \& Urry, 1994).These authors have also emphasized how cultural influences penetrate goods production principally through their integration into the design features of items.

This last example allows us to view design and fashion as homogeneous cultural industries shaped by composite inter-sectoral agglomerative connections. Some studies focus on socially entrenched interactions through which economy and culture intensely blend, creating and enhancing value (Amin \& Thrift, 2004); therefore the theoretical framework of value creation is of some relevance. Value is produced in mutual relationships among producers or creators, goods, and consumers. This process, for instance, generates sentiments that enhance the consumer perceived value. As in the Marxian value-creation model, value is conceived in relational terms; in other words, it is generated through the tangible process that produces the good but also through the dynamics of circulation and commercialization that convey the item to its market. 
As exemplified below, design and fashion consist of complementary but interdependent fluxes of value that can be switched or shared through diverse interconnected paths where reciprocal value might increase. In recent years, it has become evident that traditional sectoral borders within the design and fashion industries have been reduced. Renowned fashion brands are increasingly being drawn to design through creative, productive, and commercial circuits. They either use trade platforms such as design fairs to introduce their own furniture collection, or they cooperate with designers or design brands to fit out showrooms or flagship stores around the globe. Besides well-known architects or architecture firms, designers and fashion brands are blending so as to realize fashionable and innovative interiors or to create tailor-made solutions for the contract sector. Nevertheless fashion brands, in partnership with furniture manufacturers, transmit the symbolic lifestyle meaning of the brand through the creation of a homeware or interiors collection (i.e., Armani Home; Ittala for Issey Miyake; Jasper Conran for Wedgwood; etc.). The consumer demand for a fashionable and stylish home alongside with the idea that a fashion brand might function as a lifestyle single repository has given rise to new opportunities for fashion brands, blurring the lines between fashion industry and furniture industry even further.

The above-mentioned theoretical assumptions and the successful practical evidences confirm that fashion may profitably associate with design. As stated by McRobbie (1998), today everything is a matter of 'image industry'; therefore competitive advantage for firms must be found for instance in the production and strategic management of design and fashion knowledge, the latter being entrenched in different kinds of marketable output that can be transformed into fluxes of value (Jansson \& Power, 2010). It is therefore not unusual to see companies that were once based on designing clothes diversify into product sectors with little relation to dressmaking (hotels, homeware, interiors, etc.); or companies that were once based on designing furniture diversify into fashion, decoration, etc.

\section{LFBs and furniture design}

\section{LFBs and furniture design associations}

The furniture design sector represents a part of the broader industrial design process which merges applied science and applied art to increase the aesthetic, visual, and symbolic products' quality (Heskett; 1980). As mentioned above, 'luxury lifestyle' is turning into a catchword narrative that helps better to understand, among the various extensions of LFBs outside of their original expertise, the increasing extension represented by LFBs's inroad into furniture design to create and produce luxury homewares. Besides all the above cited tangible and intangible features that fashion and design have in common, LFBs and furniture share two other critical forms of know-how: 
design and material innovation (i.e., textile). Through such a type of intersectoral association, furniture design and fashion brands may in fact benefit from an increase of knowledge as well as a decrease of the levels of risk. A mutual infusion of high levels of expertise may then allow value-creation to be the primary intrinsic effect emerging from luxury premium sectors' intersections.

On the other side, LFBs often recur to some specular symbolic meanings pertaining to a high-quality furniture firm or brand. When the Italian luxury shoe brand Fratelli Rossetti chose to insert some of the design icons of the premium brand Cappellini for its latest catalogue, it concurrently chose to use Cappellini product assets in terms of craftsmanship, brand image, brand perception, position, prestige, etc. After all, products and brands' values for both industries primarily depend on differentiation capabilities from competitors and on intangibles assets. Therefore, the increase of symbolic intangible features such as identification, reputation (Jansson \& Power, 2010), distinctiveness or prestige becomes a fundamental strategic opportunity even if this requires that the brand cross its sectoral borders.

\section{Growing opportunities from the furniture design market}

The Design Market Monitor 2016 (Altagamma, 2016a) describes a market characterized by a strong growing potential. This fact relies on an increasing popularity of design and on the huge basin represented by the Asiatic markets. In 2015 the whole design market reached $€ 100$ billion. Moreover, the 'core design segment', which encompasses divisions such as 'living \& bedroom', 'kitchen', 'outdoor', 'bathroom' and 'lighting', and which mainly corresponds to the more comprehensive 'furniture' sector, reached $€ 32$ billion and performed a $+4 \%$ growth rate of a $+4 \%$ at constant rate, as opposed to a European market $(+4 \%)$ which is responsible for a half of the global expenditures $(47 \%)$.

The Altagamma's latest design study (2016a) has identified a particular segment, the 'high-quality furniture design market'. Asia --within its $51 \%$ of personal luxury brands consumers-- undoubtedly represents the major future growth potential for 'premium furniture design'. Another interesting market insight indicates that Italian premium furniture brands are the absolute leaders, with a market share of $30 \%$. The reason of such a success is linked to their strengthening and globally recognized skills. Italian brands consist of almost two hundred players with a turnover of $€ 50$ million.

For the aim of this paper, the Altagamma 'high-quality design market' segmentation appears to be relevant, so that from now on it will be used as a reference (2016a). This segmentation identifies four groups. The first group is formed by the 'pure design brands' represented by high-quality furniture players connoted by a strong design DNA and culture, collaborations with 
popular architects and designers, iconic products/lines, international reach (i.e., Artemide, Boffi, Kartell, Flos, Vitra, B\&B Italia, etc.). The second group consists of the 'branded retailers' who are native mono-brand retailers characterized by an upper-premium positioning (i.e., Arhaus, Rochebobois, etc.). The third group is formed by the 'personal luxury brands'. This encompasses the LFBs as diversified in home products (i.e., Fendi Casa, Kenzo Maison, etc.). The last group includes the 'premium design brands', which are players connoted by upper-premium positioning and by upperpremium lines of mainstream brands (i.e., Ligne Roset, Veneta Cucine, Burgbad, Cattelan Italia, etc.).

\section{Potentialities and strategic opportunities deriving from the association of LFBs with high-quality furniture design brands}

When looking at the Altagamma design market's representation and taking into account what has emerged until now from a cross-observation of these two worlds, LFBs and furniture design brands show diverse intersections alongside with homogenous cultural and economic issues. For instance, some of the 2016 figures of the global luxury goods market illustrate that among the accounted categories forming the market, 'personal luxury goods' (i.e., LFBs) compete not only with 'luxury cars', 'luxury cruises', etc., but also with the categories of 'fine art' and 'high-quality design'. With regard to the 2015-2016 growth, however, 'personal luxury goods' experienced a loss of a $-1 \%$, 'fine art' remained stable, whereas 'high-quality design' experienced a $+3 \%$ increase.

Growth performances appear in categories such as 'design' but also in 'luxury cruises', 'luxury food, 'luxury wines \& spirits' and 'luxury hôtellerie'. The luxury good 'experience' asset, then, appears to be of dramatic relevance. In fact, experience increases the product's success because luxury consumable experiences are strongly positive, encouraged as they are by luxury customers redirecting their purchases toward new and more personal premium pleasures (Altagamma, 2016b). In sum, besides the already mentioned similarities, LFBs and high-quality furniture design brands belong to the same luxury goods market. However, nowadays its consumption model has changed: it shows that, among other specificities, luxury consumption is essentially demanding (i.e., only really innovative brands obtain consumers' rapid reaction) and experiential.

So far, on the one hand this paper has shown that fashion and design possess a unique ability to create transversal systems and to realize reciprocally strengthening structures of value construction. On the other hand, by selecting the particular categories of LFBs and high-quality furniture design brands, this paper has also shown how the former deals with a flat market, while the latter experiences a record growth across all segments. As a 
result, collaborations with the high-quality furniture design market appears to be a great strategic opportunity for luxury fashion brands.

Once the strong points of the high-quality furniture design market's are identified, the terrain for conceive appropriate associative strategies takes shape. For instance, LFB managers should, 1) evaluate the opportunities for collaboration with categories of top high-quality furniture design's such as 'living \& bedroom'; 2) select the largest brands or the brands among them that are experiencing growth; 3) create specific emerging market-oriented strategies (i.e., Asia, Middle East, etc.); 4) conceive associative strategies through the appropriate channels, especially through direct channels (contract, retail, and e-commerce) (Altagamma, 2016a).

From a more consumer-centric angle, through associations with highquality furniture design (i.e., through brand and marketing communication strategies), LFBs can supply true innovation and be rewarded by consumers. To launch the entire new collection or some selected products in association with high-quality furniture design items, or in high-quality furniture design typical sets, circuits, spaces, public relations special events (i.e., in trade fair areas during the Design week; in the studio of a recognizable designer surrounded by his products; in high-quality furniture design' flagship stores; in dedicated issues or articles in specialized high-quality furniture magazines or websites, blogs; etc.) may stimulate consumer engagement, visually and creatively innovate brand content and 'storytelling'. High-quality furniture design products and creators are intrinsically anchored to emblematic features such as history, culture, creativity, personality, savoir-faire, tradition, aesthetics, singularity, visuality, craftsmanship, etc. The visual and/or narrated association of LFBs with some of these symbolic conveyors could impact consumer brand perception and sentiment while enhancing their luxury consumer experience.

LFBs can realize these associations in many other ways. For instance, LFBs can engage high-quality furniture designers in fashion product collaborations or create cross-sectoral best-in-class talents teams where luxury fashion designers are associated in special projects with high-quality furniture designers. If adequately communicated such strategies can make LFBs more relevant and visible. To do so, LFBs should also transform flagship stores into creative, innovative, and trend-setting spaces by rotating high-quality furniture design products or collections. In addition, flagship stores should host highquality furniture designers during selected phases of their creative and manufacturing processes open to the public. Similar processes can be activated in the ateliers of the luxury fashion firms or even in their physical industrial manufacturing spaces, for instance through special high-quality furniture designers' residency programs. In this case, designers can be hosted and can benefit from materials, tools, fabrics or simply from the overall creative 
atmosphere. Alongside with the direct benefits for designers, similar activities would immediately attract the attention of both LFBs and furniture design audiences (i.e., media, influencers, co-makers, stakeholders, opinion-makers, etc.) and, as a consequence, mediate the brands' interaction with the final consumers.

Most LFBs possess strong 'made-in' levels of connotation (i.e., French and Italian firms). At the same time, they struggle with a loss of credibility when well-informed consumers discover issues related to the introduction of mass production in fashion luxury and delocalization processes in emerging countries. Conversely, for the time being high-quality furniture design brands do not deal with the same issues, as they are still transparently strongly connected to the symbolic meanings of their country of origin (i.e., in Italy the majority of high-quality furniture design firms still manufacture in welldefined Italian industrial clusters such as the furniture district of 'Monza and Brianza'). An association with such brands enables LFBs to capture part of their country-related value while allowing them to reinforce their own value. Italy and France have a strong tradition in high-quality furniture design and luxury fashion. This is why cities such as Milan or Paris become functional places for the creation and the realization of some of the above mentioned strategies. These cities could in fact enhance the relationships between the two sectors, increase opportunities, and provide a symbolic and economic space through which to produce and replicate value.

When LFBs intersect with high-quality furniture design in such recognizable physical areas, creative knowledge proves to be intensively produced, shared, and disseminated. This creates fluxes of values that can be recognized and used also by local institutions, inhabitants, and consumers who would consequently enhance their sentiment and perception. Milan and Paris may in fact perform as centres for the creation and transfer of brand value.

\section{LFBs and collectible furniture design}

In the high-quality furniture design sector, a special category is represented by the 'collectible furniture design items' ('CFDIs'). This paper argues that this category is the most appropriate in order to conceive and put into practice effective inter-sectoral value-creation strategies that link LFBs with furniture design. There are two different sets of reasons for this. The first one derives from the CFDIs' original features. Their original primary features (i.e., functionality, reproducibility, etc.) allow to distinguish collectible furniture design items from collectible art goods. Yet these same features are also the original primary features of luxury fashion goods. As a result, these common original primary features make CFDIs and luxury fashion goods homogenous. 
The second set of reasons derives from the CFDIs' symbolic meanings and aesthetic values. In this case, the luxury perception too is taken to its extreme limits through the CFDIs' secondary additional features (rarity, exclusiveness, uniqueness, etc.). These are the same features that make CFDIs increasingly perceived and treated as art objects (i.e., they are traded in art auctions) (Bertacchini \& Friel, 2015). In sum, if on the one hand a collectible furniture design object at its origins represents a product that possesses primary tangible functions (i.e., to furnish individuals' private and public spaces and/or to decorate them), on the other hand the same object can acquire secondary intangible symbolic meanings that derive from several circumstances, such as its being part of a limited or special edition; its being a unique piece; its being a piece of a particular renowned collection; its being designed by a famous and institutionalized designer or architect; its being a representative historical or cultural icon; etc. These secondary intangible qualities linked to extraordinariness, rarity, and so on, represent the very essence of luxury. At the same time, the typical additional features of luxury goods such as high quality, high prices, and aesthetics, embody extra significant aspects of the CFDIs, often representing the reasons why they are desired, exchanged in art auctions, collected or exhibited in museums.

Hence, also in relation to symbolic benefits, LFBs and CFDIs can be considered homogenous. In fact, they are both strongly connected to figurative and non-functional implications, such as the consumer's choice of these objects and brands selected to satisfy his symbolic desire to somehow belong to a restricted and privileged class (Kapferer \& Bastien, 2009). At the same time both consumers and/or collectors of LFBs and CFDIs want to satisfy their senses and live exclusive hedonic experiences.

We believe that the two identified sets of reasons (original primary features and secondary additional features) together with other circumstances make strategic marketing associations of LFBs with high-quality furniture design even more effective. For instance, they both perform through extremely similar high-end commercial and social circuits in which their brands and products acquire meanings of exclusiveness, prestige, etc. As an example, increasingly around the globe there exist special sections in prestigious art fairs (i.e., Frieze in London, Miart in Milan, Art Paris in Paris, etc.) explicitly devoted to CFDIs. For their symbolic significances (i.e., glamour, exclusiveness, etc.) this type of fairs and events are highly comparable to the ones of the luxury fashion world.

Bertacchini and Friel (2015) have also noticed that the collectible furniture design market has been steadily growing in terms of prices. This phenomenon, in turn, gives these items the status of luxury goods. Public figures and data suggest that such rise in prices is particularly evident for precise segments, such as French and Italian design of the Thirties, Forties, 
and Fifties. Italy and France then, are -just as in the case of luxury fashion firms, products, and brands- the foremost regional references. Bertacchini and Friel show that the strong rise in prices of CFDIs depends on the huge media coverage they have received since the mid-Nineties and on the change in taste of wealthy individuals who started to diversify their art collections with highquality furniture items. Both facts have implications for any LFBs' hypothetical collaboration with collectible furniture design. On the one side, by associating with collectible furniture design LFBs might benefit from such strong media attention and coverage. On the other, association with collectible furniture design may allow LFBs to reach its target groups more effectively, since they often coincide.

From a more practical perspective, we believe that inter-sectoral strategic associations with collectible furniture design would be practicable through specific marketing communication operations, such as advertising (i.e., shootings, clipboards, etc.), direct marketing, visual merchandising, public relations (i.e., events, editorials, press releases, etc.) and sponsoring. In relation to advertising, editorials, press releases (i.e., in magazines, social networks channels, etc.), and direct marketing (i.e., catalogues, websites, etc.) an effective associative strategy may for instance focus on visuality by conceiving fashion photography's creative ideas through the insertion of iconic or recognizable CFDIs in shootings. In relation to visual merchandising, another visuality-oriented associative strategy may display iconic or recognizable CFDIs through various retail spaces (i.e., in shop windows, store's showcases, or as specific elements of the store's interior decoration). This may certainly enrich the luxury consumer experience. With regard to public relations, an effective strategy may consist in a planned systematic presence of LFBs in collectible furniture design events (i.e., private collectible furniture design galleries, etc.). Public relation strategies might even envisage to organize some of their experience-based own events in collectible furniture design typical spaces, presenting for example a new collection in a collectible furniture design gallery. Finally, with regard to sponsoring, LFBs can sponsor collectible furniture design fairs (or art fairs where special design events, programs, or sections are organized) or museums and galleries exhibitions.

\section{Conclusion}

This paper has argued that associations with high-quality furniture design products can represent for LFBs managers an effective creative and innovative brand and marketing communication strategy. This research has firstly shown the presence of congruencies between fashion and design, while identifying existent associations between the two sectors. Secondly, it has compared LFBs with the specific furniture design market by showing that such inter-sectoral association can effectively produce fluxes of value. Lastly, this 
paper has evidenced how the intersection of LFBs with the category of CFDIs can be even more successful. As such association can represent a valid process to be exploited by contemporary LFBs, some appropriate visual and experience-based strategies have been suggested. Compared to those associated to art, such strategies would be able to add value and strengthen the intangible luxury features of LFBs in an even more effective way. In sum, if LFBs can find in high-quality furniture design a symbolical substitute of the loss and the failure of the artisan's image, their association with the special segment of CFDIs can even help LFBs to compensate for the diminished sense of rarity, of exclusiveness, or of some other special features formerly connected to the industry. In order to counter these tendencies, innovative strong strategies can focus on paradigms of differentiation based on intangible, cultural, and creative resources. In general, as this study deals with a brandnew topic, it could certainly be deepened. For instance, this paper has been realized without the support of quantitative data. Future research on this topic should then envisage to collect primary data aimed, for instance, at examining other fundamental processes of these two markets such as structural preconditions, direct interactions, transfer of knowledge forms, and power relations. Another suggestion for additional investigation on the connections between luxury fashion and high-quality furniture design firms and brands regards the implications that these intersections might have for cities or specific urban districts, where these interferences are highly concentrated. As shown by this paper, Milan and Paris function as nodes for the formation and transfer of creative fluxes of value and brand value for both sectors of fashion and design. These cities may hence represent the ideal settings for a close study on this topic.

\section{References:}

1. Altagamma. (2016a). Design market monitor 2016. Retrieved from https://www.altagamma.it

2. Altagamma. (2016b). Altagamma 2016 worldwide luxury market monitor. D’Arpizio, C. Retrieved from https://www.altagamma.it

3. Amin, A., \& Thrift, N. (2004). Introduction. In A. Amin \& N. Thrift (Eds.), The Blackwell Cultural Economy Reader. Oxford: Blackwell.

4. Atwal, G., \& Williams, A. (2009). Luxury brand marketing - the experience is everything! Journal of Brand Management, 16, "338$346 "$.

5. Bain \& Company. (2016). Luxury goods worldwide market study, FallWinter 2016: As luxury resets to a new normal, strategy become paramount. D’Arpizio C., Levato, F., Zito D., Kamel, M.A., \& de Montgolfier, J. Retrieved from http: www.bain.com.

6. Berry, C. J. (1994). The idea of luxury - A conceptual framework and 
historical investigation. Cambridge: Cambridge University Press.

7. Bertacchini, E., \& Friel, M. (2015). Determining the value of modern and contemporary furniture design: An exploratory investigation. Unpublished manuscript, Department of Economics and Statistics "Cognetti de Martiis", Università degli Studi di Torino.

8. Breward, C., \& Gilbert, D. (2006). Fashion's world cities. Oxford: Berg.

9. Catry, B. (2003). He great pretenders: The magic of luxury goods. Business Strategy Review, 14, "10-17".

10. Chadha, R., \& Husband, P. (2007). The cult of the luxury brand. London: Nicholas Brealey Publishing.

11. Codignola, F., \& Rancati, E. (2016). The blending of luxury fashion brands and contemporary art: A global strategy for value creation. In A. Vecchi \& C. Buckley (Eds.), Handbook of Research on Global fashion Management and Merchandising. Hershey, PA: IGI Global.

12. Currid, E. (2007). The Warhol Economy: How Fashion, Art, and Music Drive New York City. Princeton, NJ: Princeton University Press.

13. Dubois, B., Laurent, G., \& Czellar, S. (2001). Consumer rapport to luxury: Analyzing complex and ambivalent attitudes. Les Cahiers de Recherche, 33, "1-56". Retrieved from http://www.hec.fr

14. Eisner, E. W. (2002). The arts and the creation of mind. New Haven, CT: Yale University Press.

15. Hansen, J., \& Wanke, M. (2011). The abstractness of luxury. Journal of Economic Psychology, 32, "789-796".

16. Heine, K. (2010). The personality of luxury fashionbrands. Journal of Global Fashion Marketing, 1, "154-163".

17. Heskett, J. (1980). Industrial Design. London: Thames and Hudson.

18. Jansson, J., \& Power, D. (2010). Fashioning a global city: Global city brand channels in the fashion and design industries. Regional Studies, 44, "889-904".

19. Kapferer, J. N., \& Bastien, V. (2009). The specificity of luxury management: Turning marketing upside down. Journal of Brand Management, 16, "311-322".

20. Kapferer, J. N., \& Bastien, V. (2012). The luxury strategy. London: Kogan Page.

21. Karpik, L., \& Scott, N. (2010). Valuing the unique. Princeton: Princeton University Press.

22. KEA European Affairs. (2006). The Economy of Culture in Europe. Brussels: European Commission.

23. Keller, K. L. (2009). Managing the growth tradeoff: Challenges and opportunities in luxury branding. Journal of Brand Management, 16, “290-301". 
24. Lash, S., \& Urry, J. (1994). Economies of Signs and Space. London: Sage.

25. Matthiesen, I., \& Pau, I. (2005). The "Hugo Boss" connection: Achieving global brand consistency. Brand Management, 12, "325$338 "$ ".

26. McRobbie, A. (1998). British Fashion Design: Rag Trade or Image Industry? London: Routledge.

27. Mirzoeff, N. (2006). On visuality. Journal of Visual Culture, 5, "5379 ".

28. Nia, A., \& Zaichkowsky, J. (2000). Do counterfeits devalue the ownership of luxury brands? Journal of Product and Brand Management, 9, "485-497".

29. Okonkwo, U. (2009). The luxury brand strategy challenge. Journal of Brand Management, 16, "287-289".

30. Phau, I., \& Prendergast, G. (2000). Consuming luxury brands: The relevance of the rarity principle. The Journal of Brand Management, 8 , "122-138".

31. Potvin, J. (2009). The places and spaces of fashion, 1800-2007. London: Routledge.

32. Quinn, B. (2003). The fashion of architecture. New York: Berg Publishers.

33. Santagata, W. (2004). Creativity, fashion and market behavior. Routledge Studies in International Business and the World Economy, 33, "75-90". Retrieved from https://www.routledge.com

34. Seo, Y., \& Buchanan-Oliver, M. (2015). Luxury Branding: The Industry, Trends, and Future Conceptualizations. Asia Pacific Journal of Marketing and Logistics, 27, "82-98".

35. So, J. T., Parsons, A. G., \& Yap, S. (2013). Corporate Branding, Emotional Attachment and Brand Loyalty: The Case of Luxury Fashion Branding. Journal of Fashion Marketing Management, 17, "403-423".

36. The Boston Consulting Group. (2010). The new world of luxury. Bellaïche, J.M., Mei-Pochtler, A. \& Hanish, D. Retrieved from https://www.bcgperspectives.com/

37. Throsby, D. (2001). Economics and Culture. Cambridge: Cambridge University Press.

38. Truong, Y., McColl, R., \& Kitchen, P. J. (2009), New luxury brand positioning and the emergence of masstige brands, Journal of Brand Management, 16, “375-382”. 